\title{
Quantitative Anatomy of the Trachea of the Giraffe (Giraffa camelopardalis rothschildi)
}

\author{
Anatomía Cuantitativa de la Tráquea de la Jirafa (Giraffa camelopardalis rothschildi)
}

Ivana Cano \& William Pérez

CANO, I. \& PÉREZ, W. Quantitative anatomy of the trachea of the Giraffe (Giraffa camelopardalis rothschildi). Int. J. Morphol., 27(3):905-908, 2009.

SUMMARY: We described the macroscopic and quantitative anatomy of the trachea of the Giraffe (Giraffa camelopardalis rothschildi). The trachea of one juvenile male giraffe ( 25 months of age) weighing $754 \mathrm{~kg}$ was used in this study. The length of the neck was $125 \mathrm{~cm}$. The trachea had $107 \mathrm{~cm}$ in length on its cervical part and $18 \mathrm{~cm}$ on its thoracic part. The total number of cartilage was 87.74 at the neck and 13 at the thorax. The general shape of the duct was mostly circular. The separation of the dorsal ends of the tracheal cartilages was pronounced in the first half of the cervical trachea, reducing caudally and overlapping in the thoracic trachea. In the caudal part the trachea had a tracheal bronchus for the cranial lobe of the right lung and the end of the trachea was divided into two main bronchi, where the left was larger in diameter.

KEY WORDS: Anatomy; Respiratory aparatus; Trachea; Wild animal; Quantitative study.

\section{INTRODUCTION}

The giraffe (Giraffa camelopardalis) is the largest extant ruminant (Owen-Smith 1988). Giraffes live in open woodland and wooded grassland areas in Africa south of the Sahara Desert.

To our knowledge the anatomy of the giraffe is scarcely studied in comparison with domestic animals and camelids. According to the textbook of Barone (1997) the trachea of the giraffe has more of 200 cartilages.

The trachea in the domestic mammals was studied quantitatively: in the dog (Dabanoglu et al., 2001), in the horse (Freitas et al., 2001), in the indian buffalo (Peshin \& Prakash, 1975), and in camels (Kumar et al., 1992). Harrison (1980) studied the biomechanics of the giraffe's larynx and trachea and reported for a male animal a total length of $2.3 \mathrm{~m}$ for the trachea, with a maximum width of $51 \mathrm{~mm}$, and a minimum width of $35 \mathrm{~mm}$. He did not specify to which parts of the trachea these measurements belonged to. He stated that the trachea is oval in cross-section.

To our knowledge, quantitative studies of the trachea of the giraffe have not been published so far, and therefore, we wanted to make the most of the opportunity of the one giraffe dissection to carry out this study.

\section{MATERIAL AND METHOD}

The trachea of one giraffe was used in this study. At a Zoological Garden of Uruguay, a juvenile male giraffe (25 months of age) weighing $754 \mathrm{~kg}$ died because of acute traumatic pericarditis. The animal was dissected at the Veterinary Faculty of the University of Montevideo. After removal of the trachea from the neck and thoracic cavity the trachea was studied and documented by digital photography (Nikon D200).

After dissection of all fasciae, the length of the trachea (from the cranial border of the first tracheal ring up to the bifurcation) was measured with a standard measuring tape and the tracheal rings counted. After fixation in formalin the inner transverse (IT), outer transverse (OT), inner vertical (IV) and outer vertical (OV) diameters were measured at the level of each tracheal ring with the aid of a calliper in 


\begin{tabular}{|c|c|c|c|c|c|c|c|c|c|}
\hline Cartilage & $\mathrm{OV}$ & IT & $\mathrm{OV}$ & OT & CCL1 & CCL2 & CCL3 & CCL4 & DS \\
\hline & \multicolumn{9}{|c|}{ Cervical part of the trachea } \\
\hline 1 & 36 & 37 & 40 & 43 & 24 & 11 & 12 & 15 & 12 \\
\hline 2 & 37 & 37 & 44 & 44 & 17 & 14 & 14 & 14 & 20 \\
\hline 3 & 38 & 37 & 45.5 & 45 & 15 & 18.5 & 15 & 17 & 19 \\
\hline 4 & 39 & 36.5 & 46 & 44.5 & 11 & 15 & 14 & 13 & 19 \\
\hline 5 & 37 & 36 & 44 & 43 & 8 & 12 & 13 & 13 & 16 \\
\hline 6 & 36 & 34 & 43.5 & 42 & 12 & 11 & 15 & 16 & 14.5 \\
\hline 7 & 35 & 34 & 43 & 42 & 16 & 18 & 19 & 19 & 13 \\
\hline 8 & 36 & 34 & 43 & 41 & 17 & 20 & 19 & 21 & 14 \\
\hline 9 & 33.5 & 33 & 40 & 39 & 14 & 16 & 17 & 15 & 11 \\
\hline 10 & 33 & 31 & 41 & 40 & 15 & 15 & 15 & 15 & 11 \\
\hline 11 & 34 & 31 & 41 & 39 & 8 & 15 & 13 & 12 & 10 \\
\hline 12 & 33 & 33 & 41 & 40 & 12 & 16 & 17 & 16 & 11 \\
\hline 13 & 33 & 33 & 40 & 40 & 12 & 15 & 16 & 16 & 10 \\
\hline 14 & 33 & 32 & 39 & 40 & 12 & 14 & 16 & 17 & 11 \\
\hline 15 & 32 & 33 & 40 & 41 & 8 & 14 & 14 & 15 & 11 \\
\hline 16 & 32 & 34 & 39 & 41 & 12 & 17 & 16 & 19 & 10 \\
\hline 17 & 33 & 33 & 40 & 40 & 13 & 15 & 19 & 17 & 13 \\
\hline 18 & 33 & 32 & 40 & 39 & 11 & 14 & 16 & 14 & 9 \\
\hline 19 & 33 & 31 & 39 & 39 & 13 & 13 & 15 & 15 & 10 \\
\hline 20 & 33 & 32 & 39 & 39 & 12 & 17 & 16 & 18 & 11 \\
\hline 21 & 33 & 32 & 40 & 38 & 12 & 17 & 16 & 15 & 7 \\
\hline 22 & 33 & 32 & 40 & 38 & 11 & 16 & 17 & 15 & 9 \\
\hline 23 & 32 & 32 & 39 & 39 & 11 & 13 & 12 & 15 & 8 \\
\hline 24 & 32 & 33 & 39 & 40 & 6 & 12 & 12 & 12 & 11 \\
\hline 25 & 33 & 32 & 39 & 38 & 9 & 11 & 12 & 10 & 7 \\
\hline 26 & 32 & 33 & 39 & 40 & 11 & 16 & 12 & 11 & 7 \\
\hline 27 & 33 & 32 & 40 & 39 & 17 & 18 & 19 & 22 & 11 \\
\hline 28 & 33 & 33 & 40 & 39 & 11 & 14 & 16 & 16 & 9 \\
\hline 29 & 33 & 33 & 39 & 40 & 12 & 15 & 15 & 14 & 10 \\
\hline 30 & 34 & 32 & 40 & 38 & 9 & 13 & 14 & 11 & 7 \\
\hline 31 & 34 & 32 & 40 & 39 & 12 & 14 & 14 & 14 & 8 \\
\hline 32 & 34 & 32 & 41 & 38 & 7 & 9 & 15 & 15 & 15 \\
\hline 33 & 34 & 32 & 40 & 39 & 11 & 14 & 14 & 14 & 10 \\
\hline 34 & 35 & 30 & 40 & 38 & 9 & 15 & 13 & 15 & 7 \\
\hline 35 & 33 & 33 & 41 & 39 & 13 & 16 & 17 & 15 & 8 \\
\hline 36 & 34 & 33 & 40 & 39 & 11 & 15 & 16 & 16 & 6 \\
\hline 37 & 34 & 32 & 41 & 38 & 13 & 16 & 16 & 16 & 6 \\
\hline 38 & 35 & 32 & 39 & 39 & 12 & 17 & 17 & 17 & 5 \\
\hline 39 & 34 & 32 & 40 & 40 & 15 & 15 & 14 & 16 & 8 \\
\hline 40 & 35 & 32 & 40 & 39 & 7 & 14 & 15 & 12 & 7 \\
\hline 41 & 34 & 33 & 39 & 40 & 11 & 13 & 14 & 12 & 7 \\
\hline 42 & 34 & 33 & 40 & 40 & 8 & 14 & 13 & 14 & 9 \\
\hline 43 & 33 & 33 & 40 & 39 & 12 & 15 & 15 & 16 & 7 \\
\hline 44 & 34 & 33 & 40 & 39 & 9 & 13 & 12 & 15 & 8 \\
\hline 45 & 34 & 32 & 41 & 40 & 14 & 16 & 16 & 15 & 5 \\
\hline 46 & 34 & 32 & 40 & 39 & 10 & 17 & 16 & 19 & 7 \\
\hline 47 & 35 & 32 & 41 & 39 & 13 & 17 & 13 & 16 & 7 \\
\hline 48 & 35 & 32 & 43 & 39 & 15 & 19 & 20 & 20 & 7 \\
\hline 49 & 36 & 31 & 42 & 39 & 10 & 17 & 15 & 15 & 6 \\
\hline 50 & 34 & 32 & 41 & 41 & 14 & 18 & 14 & 17 & 9 \\
\hline 51 & 34 & 33 & 41 & 40 & 11 & 16 & 18 & 20 & 6 \\
\hline 52 & 34 & 34 & 40 & 40 & 15 & 15 & 15 & 16 & 6 \\
\hline 53 & 34 & 32 & 41 & 40 & 14 & 16 & 15 & 18 & 6 \\
\hline 54 & 35 & 33 & 42 & 40 & 10 & 16 & 12 & 13 & 4 \\
\hline 55 & 33 & 34 & 39 & 41 & 12 & 18 & 20 & 19 & 4 \\
\hline 56 & 33 & 33 & 39 & 41 & 12 & 15 & 15 & 15 & 5 \\
\hline 57 & 32 & 33 & 39 & 39 & 11 & 13 & 14 & 15 & 4 \\
\hline 58 & 31 & 34 & 37 & 40 & 11 & 14 & 14 & 16 & 4 \\
\hline 59 & 33 & 33 & 39 & 40 & 8 & 15 & 12 & 16 & 7 \\
\hline 60 & 32 & 32 & 40 & 40 & 15 & 13 & 16 & 14 & 3 \\
\hline 61 & 34 & 32 & 42 & 40 & 11 & 14 & 13 & 14 & 1 \\
\hline 62 & 34 & 31 & 45 & 38 & 13 & 16 & 13 & 17 & 3 \\
\hline 63 & 35 & 28 & 45 & 35 & 15 & 15 & 17 & 18 & 7 \\
\hline 64 & 35 & 28 & 45 & 34 & 13 & 18 & 14 & 17 & 2 \\
\hline 65 & 36 & 29 & 43 & 35 & 11 & 12 & 16 & 12 & 2 \\
\hline 66 & 36 & 29 & 44 & 36 & 13 & 11 & 10 & 10 & 1 \\
\hline 67 & 35 & 28 & 43 & 35 & 12 & 16 & 14 & 7 & 1 \\
\hline 68 & 35 & 29 & 45 & 35 & 9 & 18 & 19 & 12 & 0 \\
\hline 69 & 36 & 29 & 41 & 35 & 22 & 18 & 19 & 21 & 2 \\
\hline 70 & 35 & 29 & 40 & 34 & 13 & 17 & 15 & 18 & 0 \\
\hline 71 & 36 & 30 & 40 & 35 & 19 & 14 & 13 & 17 & 2 \\
\hline 72 & 34 & 30 & 40 & 35 & 10 & 13 & 13 & 14 & 3 \\
\hline 73 & 34 & 30 & 40 & 35 & 10 & 14 & 14 & 16 & 3 \\
\hline 74 & 33 & 30 & 40 & 36 & 15 & 15 & 17 & 15 & 0 \\
\hline
\end{tabular}

similar form to the previous study of the trachea of the dog by Dabanoglu et al. Furthermore, the distance between the dorsal ends of each ring was measured dorsally (DS), as was the cranio-caudal length of each ring (CCL). CCL 1 was measured in the dorsal part of the rings, CCL 2 in the ventral part, CCL 3 in the left side and $\mathrm{CCL} 4$ in the right side.

Terms are used in agreement with the Nomina Anatomica Veterinaria (2005)

\section{RESULTS}

The length of the neck was $125 \mathrm{~cm}$. The trachea was $107 \mathrm{~cm}$ in length on its cervical part and $18 \mathrm{~cm}$ on its thoracic part. The total number of cartilages was 87.74 belonged to the cervical portion and 13 to the thoracic part.

Table I shows the measurements described in Material and Method section at the each tracheal ring. The figure 1 (Fig. 1) shows the tracheal ring diameters at all levels in the giraffe.

The general shape of the duct was mostly circular. The thickness of the cartilage rings (Fig. 2) was constant throughout the trachea. In several places the cartilages were fused. The separation of the dorsal endsof the tracheal cartilages was pronounced in the first half of the cervical trachea, decreasing caudally and overlapped in the thoracic trachea (Fig. 3).

On the right side, at the level of cartilage number 83 emerged a tracheal bronchus for the cranial lobe of the right lung (Fig. 3). The emergence of the tracheal bronchus was $7 \mathrm{~cm}$ from the end of the trachea. The diameter of

Table I. Diameters of each tracheal rings: inner transverse (IT), outer transverse (OT), inner vertical (IV) and outer vertical (OV). Distance between the dorsal ends of each ring (DS), and cranio-caudal length of each ring (CCL). CCL 1 was measured in the dorsal part of the rings, CCL 2 in the ventral part, CCL 3 in the left side and CCL 4 in the right side. 


\begin{tabular}{llllllllll}
\hline \multicolumn{10}{c}{ Thoracic part of the trachea } \\
\hline 75 & 35 & 30 & 42 & 36 & 11 & 15 & 15 & 16 & 2 \\
76 & 32 & 30 & 40 & 35 & 13 & 16 & 18 & 17 & 1 \\
77 & 30 & 30 & 39 & 36 & 14 & 15 & 15 & 14 & 0 \\
78 & 32 & 31 & 39 & 36 & 12 & 14 & 14 & 17 & 1 \\
79 & 34 & 29 & 40 & 35 & 14 & 18 & 20 & 18 & 1 \\
80 & 35 & 30 & 40 & 36 & 14 & 17 & 15 & 14 & 0 \\
81 & 36 & 33 & 42 & 36 & 17 & 17 & 24 & 21 & 0 \\
82 & 35 & 35 & 45 & 40 & 15 & 16 & 15 & 15 & 0 \\
83 & 37 & 31 & 49 & 41 & 15 & 24 & 15 & 14 & 0 \\
84 & 34 & 26 & 47 & 33 & 12 & 14 & 14 & 9 & 0 \\
85 & 33 & 26 & 46 & 36 & 14 & 11 & 25 & 17 & 0 \\
86 & 32 & 29 & 45 & 37 & 9 & 10 & 5 & 11 & 0 \\
87 & 34 & 28 & 41 & 34 & 13 & 10 & 7 & 9 & 0 \\
\hline
\end{tabular}

the tracheal bronchus was $20 \mathrm{~mm}$ dorsoventrally and measured $13 \mathrm{~mm}$ transversally.

The right main bronchus had a dorsoventral diameter of $23 \mathrm{~mm}$ and $19 \mathrm{~mm}$ transversally. The left main bronchus had a dorso-ventral diameter of $31 \mathrm{~mm}$ and $23 \mathrm{~mm}$ transversally. The tracheal carina had a thickness of $8 \mathrm{~mm}$.

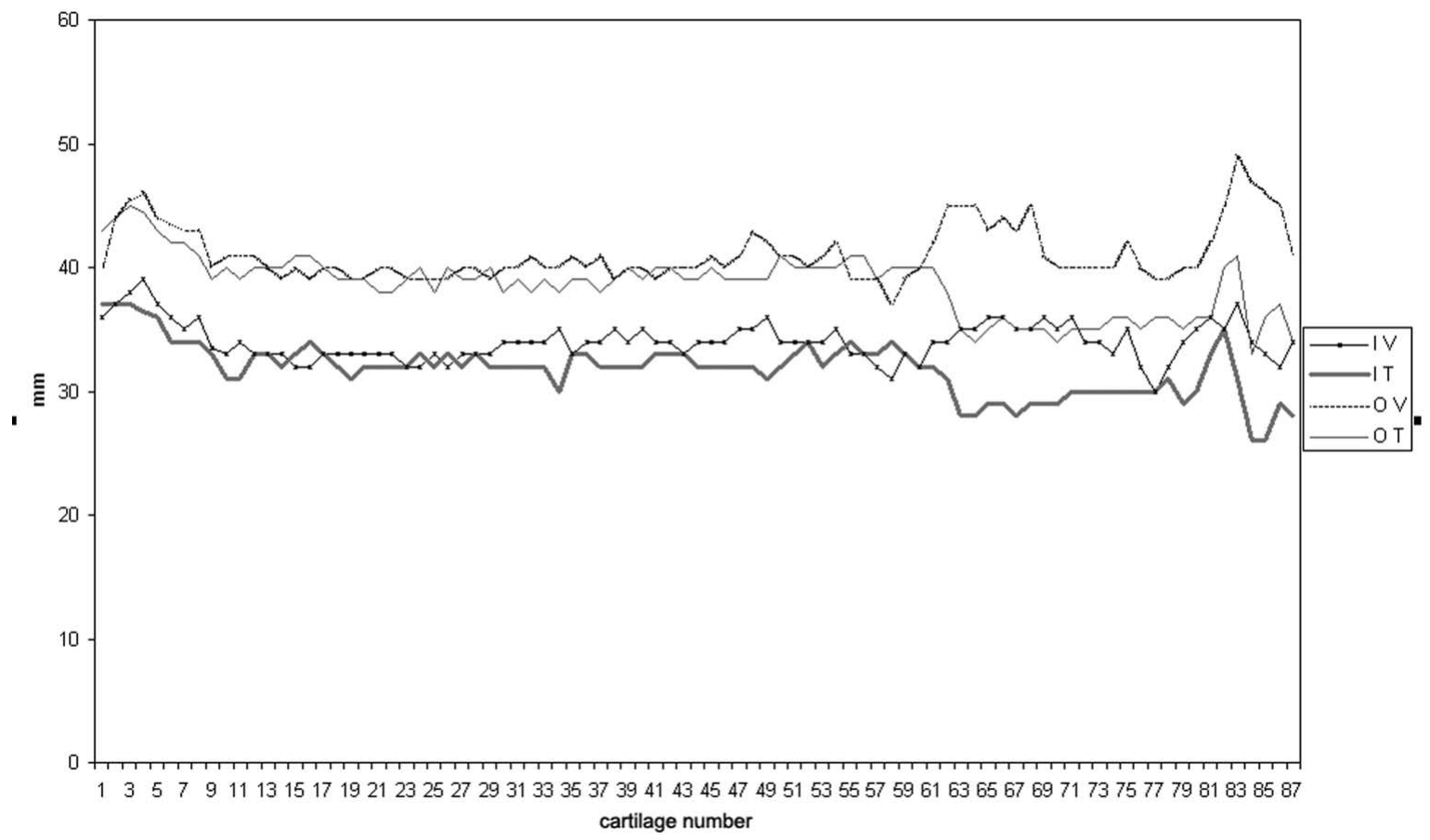

Fig. 1. Tracheal ring diameters at all levels in the giraffe. IT: inner transverse; OT. Outer transverse; IV. Inner vertical and OV. Outer vertical.
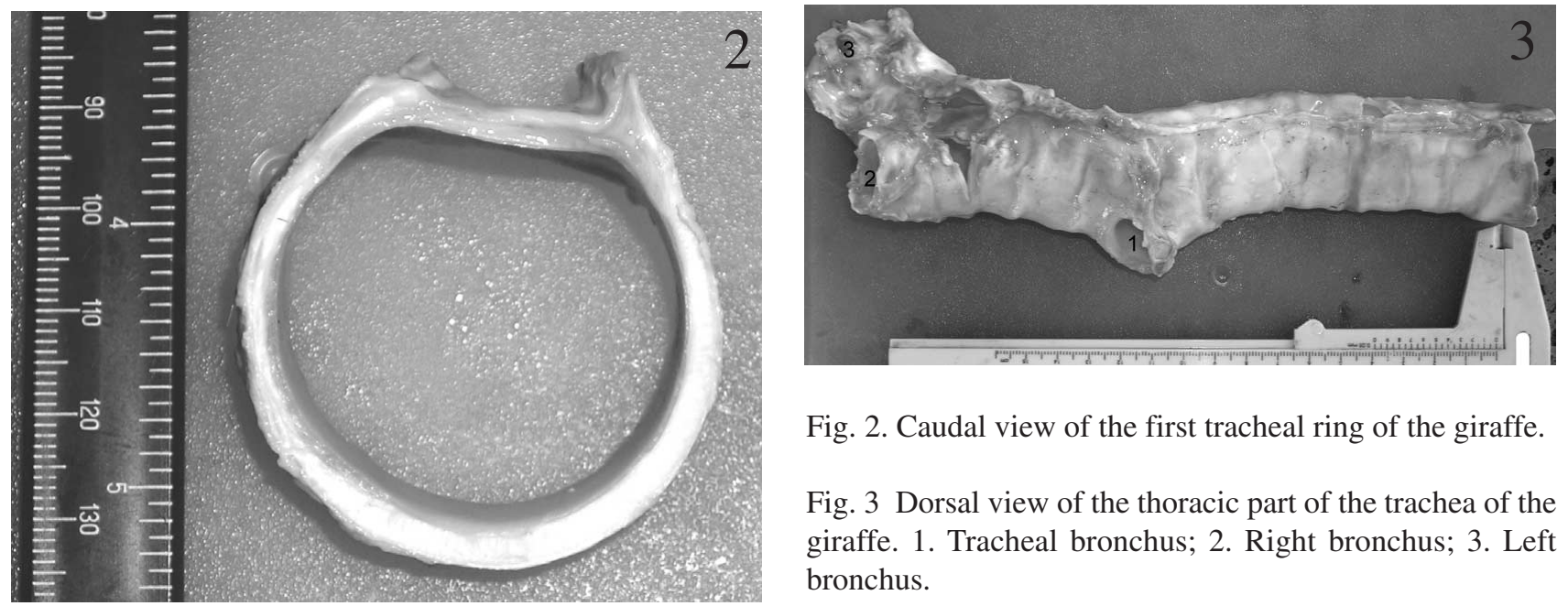

Fig. 2. Caudal view of the first tracheal ring of the giraffe.

Fig. 3 Dorsal view of the thoracic part of the trachea of the giraffe. 1. Tracheal bronchus; 2. Right bronchus; 3. Left bronchus. 


\section{DISCUSSION}

The total number of cartilages was less than was reported by Barone (1997) and strikingly low, as is the length of the thoracic part. Most of the trachea was in the neck. The bovine and equine trachea consists of 48-60 cartilages. However, the number of the tracheal cartilages is not constant in all species and varies even in animals of the same species. Occasionally, adjacent cartilages become partly or completely fused. This is seen most often in the pig and least often in the ruminants. The giraffe studied despite being ruminant had coalescence of several cartilages.

Equally variable is the cross sectional appearance of the trachea (Nickel et al., 1979). In the horse, the internal diameters of the tracheal rings measured indicated a predominance of an elliptic shape of the trachea (Freitas et al.), unlike the circular shape of the giraffe studied. Notwithstanding Harrison indicated that the trachea had an oval section but we observed this only on a few parts of the duct.
The trachea of the ox displays marked differences in shape in live and in dead animals, due principally to changes in tension of the trachealis and the annular ligaments. In the live animal, the trachea is more or less oval, but after death it becomes compressed laterally. (Nickel et al.). Probably the same thing happens in the giraffe, but also our material was studied after fixation in formalin.

In the caudal part of the trachea of the horse, small overlapping cartilaginous plates form part of the dorsal wall where the ends of the tracheal cartilages do not meet. (Nickel et al.).

Because only one animal was studied, we can not know whether there are differences in the trachea between sexes. In male horses there is more cartilage than in mares (Freitas et al.).

The main limitation of our study was that we used one animal, but this work is a further contribution to the study of the anatomy of this animal, which must be continued with other works of the anatomy of the respiratory apparatus.

CANO, I. \& PÉREZ, W. Anatomía cuantitativa de la tráquea de la jirafa (Giraffa camelopardalis rothschildi). Int. J. Morphol., 27(3):905-908, 2009.

RESUMEN: Describimos la anatomía macroscópica y cuantitativa de la tráquea de la jirafa (Giraffa camelopardalis rothschildi). La tráquea de una jirafa macho joven ( 25 meses de edad), con un peso $754 \mathrm{~kg}$ fue utilizada en este estudio. La longitud del cuello era de $125 \mathrm{~cm}$. La tráquea tuvo $107 \mathrm{~cm}$ de longitud en su parte cervical y $18 \mathrm{~cm}$ en su parte torácica. El número total de cartílagos fue de 87,74 en el cuello y 13 en el tórax. La forma general de la vía fue principalmente circular. La separación de los extremos dorsales de los cartílagos traqueales se pronunció en la primera mitad de la tráquea cervical, reduciéndose caudalmente y superponiéndose en la tráquea torácica. En la parte caudal la tráquea tenía un bronquio traqueal para el lobo craneal del pulmón derecho y el final de la tráquea se dividió en dos bronquios principales, donde el izquierdo fue de mayor diámetro.

PALABRASCLAVE: Anatomía; Aparato respiratorio; Tráquea; Animal salvaje; Estudio cuantitativo.

\section{REFERENCES}

Barone, R. Anatomie comparée des Mammifères domestiques. Edit. 3 (Splanchnologie 1: Appareilsdigestif et respiratoire). Paris, Vigot Fréres, 1997. V. 3.

Dabanoglu, I.; Ocal, M. K. \& Kara, M. E. A Quantitative Study on the Trachea of the Dog. Anat. Histol. Embryol., 30:57-9, 2001.

Freitas, R. R. D.; Pogliani, F. C.; Moretti Junior, N.; Irino, E. T.; Stopiglia, A. J.; Macruz, R.; Fantoni, D. T. \& Jatene, F. B. Tracheal morphometrics in the Thoroughbred horse. J. Eq. Vet. Sci., 21:242-5, 2001.

Harrison, D. F. Biomechanics of the giraffe larynx and trachea. Acta Otolaryngol., 89:258-64, 1980.

Kumar, P.; Singh, G. Nagpal, S. K. Dhingra, L. D. Tracheal dimensions of camel. Indian J. Anim. Sci., 62:140-1, 1992.

Nickel, R.: Schummer, A. \& Seiferle, E. The Viscera of the Domestic Mammals. 2. ed. Verlag, Verlag Paul Parey, 1979.
Nomina Anatomica Veterinaria (NAV). $5^{\text {th }}$ ed. International Committee on Veterinary Gross Anatomical Nomenclature (I.C.V.G.A.N.). 2005. http://www.wava-amav.org/Downloads/ nav_2005.pdf

Owen-Smith, N. Megaherbivores - the influence of very large body size on ecology. Cambridge, Cambridge University Press, 1988.

Peshin, P. K. \& Prakash, P. A note on the quantitative anatomical study of the trachea in the Indian buffalo(Bubalus bubalis). Anat. Anz., 138:463-7, 1975.

\section{Correspondence to:}

William Pérez

Area of Anatomy, Faculty of Veterinary Medicine

University of Uruguay

Lasplaces 1620 ,

11600 Montevideo

URUGUAY

Email: vetanat@gmail.com

Received: 13-03-2009

Accepted: 27-06-2009 